\title{
Estratégias de Humanização nos Caps: Relato de Experiência de Residentes Multiprofissionais
}

\author{
Santos, Karolyne Souza dos; Martinho, Jessica Silva; Carvalho, Jhéssyca Dias de; \\ Monteiro, Elisangela Carvaló \\ Universidade Estadual do Pará — karolynesouza09santos@yahoo.com.br
}

\begin{abstract}
INTRODUÇÃO: Os Centros de Atenção Psicossocial (CAPS) são serviços de saúde do Sistema Único de Saúde (SUS), que surgiram como estratégia na assistência à Saúde Mental, na perspectiva da Reforma Psiquiátrica, cujo objetivo consiste em oferecer tratamento especializado a pessoas em sofrimento psíquico e sua ressocialização. no serviço, os usuários recebem assistência multiprofissional. o acolhimento é a "porta de entrada", uma estratégia de humanização, uma ferramenta de intervenção na qualificação da escuta, de acesso com responsabilização e resolutividade, além de estabelecer uma relação entre o usuário e família com os profissionais e serviço, sendo uma das diretrizes de maior relevância da Política Nacional de Humanização (PNH) do SUS. o Projeto Terapêutico Singular (PTS) é, também, uma estratégia de humanização do SUS, que consiste em propostas de condutas terapêuticas articuladas entre a equipe interdisciplinar e 0 usuário nesse contexto, a fim de proporcionar o acompanhamento clínico e a reinserção social. OBJETIVO: Relatar experiências vivenciadas pelos Residentes Multiprofissionais em Atenção à Saúde Mental no que se refere à humanização do cuidado ao portador de transtorno mental, por meio das estratégias de Acolhimento e PTS. METODOLOGIA: na elaboração deste participaram residentes das categorias: Psicologia, Terapia Ocupacional, Serviço Social e Enfermagem. o período da prática se deu nos meses de setembro a novembro de 2013 em um CAPS localizado em Belém-PA, onde foi possível participar de atividades, como a realização do acolhimento e a construção de PTS. Enquanto residentes, realizamos acolhimentos nas datas e horários referentes aos nossos respectivos preceptores de prática. Nesse momento, a conversa foi realizada em consultório, para a busca de informações atuais e da história pregressa de forma reservada, favorecendo a formação de vínculo. a partir da escuta buscamos a resolutividade das necessidades. em outro momento construímos o PTS, que incorpora a noção interdisciplinar. Após avaliação compartilhada, foram acordados procedimentos terapêuticos junto ao usuário e família. RESULTADOS: As estratégias de humanização resultaram na sensibilização das famílias e esclarecimentos de dúvidas acerca do sofrimento psíquico dos usuários, favorecendo o fortalecimento de vínculo, construção de sua autonomia e adesão ao tratamento. Tivemos dificuldade com a presença do modelo médico-psiquiátrico, evidenciado pela pouca participação, integração e valorização da maior parte da equipe nas discussões para a construção do PTS. CONSIDERAÇÕES FINAIS: Os CAPS, conforme os princípios e diretrizes que regem as políticas de saúde mental e de humanização no SUS devem assumir uma função social que vai além do fazer meramente técnico do tratar, tendo a pessoa em sofrimento psíquico como um ser integral, com direito a plena participação e inclusão na comunidade.
\end{abstract}

Santos, Karolyne Souza dos; Martinho, Jessica Silva; Carvalho, Jhéssyca Dias de; Monteiro, Elisangela Carvaló. Estratégias de Humanização nos Caps: Relato de Experiência de Residentes Multiprofissionais. In: Anais do Congresso Internacional de Humanidades \& Humanização em Saúde [= Blucher Medical Proceedings, num.2, vol.1]. São Paulo: Editora Blucher, 2014. ISSN 2357-7282

DOI 10.5151/medpro-cihhs-10651 